\title{
Adult Granulosa Cell Tumors: Clinical Characteristics, Outcomes and Prognostic Factors for Recurrence at Early Stages
}

\section{Baki ERDEM ${ }^{\mathrm{a}}$ \\ (1) Osman AŞICIOĞLUa, \\ (1) Illkbal TEMEL YÜKSELa, \\ - B Berna ASLAN ÇETINa, \\ D Nur Betül ARSLANa, \\ D Suat Can ULUKENT', \\ (D) Ipek Yıldız ÖZAYDINc, (1) Özgür AKBAYIR}

Departments of

aGynecologic Oncology,

${ }^{b}$ General Surgery,

'Pathology,

Kanuni Sultan Süleyman Training and

Research Hospital,

İstanbul, TURKEY

\section{Received: 11.12.2018}

Received in revised form: 08.02.2019

Accepted: 13.02.2019

Available online: 26.02 .2019

Correspondence:

Berna ASLAN ÇETIN

Kanuni Sultan Süleyman Training and

Research Hospital,

Department of Gynecologic Oncology, İstanbul, TURKEY

bernaaslan14@ hotmail.com

\begin{abstract}
Objective: The objectives of this study were to conduct a retrospective review of patients with adult granulosa cell tumors (AGCTs) to validate the effect of full surgical staging and adjuvant chemotherapy, and to identify the factors influencing disease-free survival (DFS) and overall survival (OS). Material and Methods: The database and patient files available at our gynecological oncology department were searched to identify women who had undergone primary surgery for an ovarian tumor and whose final diagnosis was stage I/II AGCT. A total of 41 patients with earlystage AGCT were included in the analysis. Results: The majority of the cases were Stage I AGCT (63.4\%). The median OS of the patients was 54.3 months. Full stage surgery, age, and lymphadenectomy were not independent risk factors for the involvement of lymph nodes in AGCTs. For patients with full surgical staging, pelvic and para-aortic lymphadenectomy were not independent prognostic factors for DFS and OS. Conclusion: Initial stage, age, lymphadenectomy, and full stage surgery did not influence DFS, OS, or recurrence of AGCTs. Furthermore, age, bilaterality, and preoperative ultrasound image did not influence the involvement of lymph nodes in AGCTs.
\end{abstract}

Keywords: Adult granulosa cell tumor; lymphadenectomy; early stage; recurrence

varian adult granulosa cell tumors (AGCTs) represent less than 5\% of all ovarian malignancies. ${ }^{1,2}$ AGCTs have low malignant potential and grow slowly. ${ }^{3-5}$ Most of the AGCTs can be diagnosed at early stages due to hormones produced by these tumors. On the other hand, recurrences occur in nearly $20 \%$ of the early-stage cases and about $50 \%$ of the advanced-stage patients die due to recurrence. ${ }^{6}$ Although AGCT may be asymptomatic, it can cause abdominal or pelvic pain due to severe and abnormal uterine bleeding as a consequence of the hormone secretion. However, the absence of specific symptoms and tumor markers makes the diagnosis difficult. ${ }^{7,8}$

The primary treatment for patients with AGCT is surgery, which is especially effective at the early stages. The need for lymphadenectomy in these tumors is still controversial. In a previous study, the involvement of lymph nodes in AGCTs was reported to be $5 \% .{ }^{9}$ It has been reported that $15 \%$ of the initial recurrences are in retroperitoneal lymph nodes. ${ }^{10}$ Another contentious factor in the treatment of AGCT is the role of adjuvant chemotherapy (ACT). The type of therapy and patient groups needing this therapy are not clear. The effect of ACT regimens, particularly at the early 
stages, remains a mystery. Previous studies have reported that certain factors, including the stage of tumor, tumor size, tumor rupture, age at diagnosis, nuclear atypia, mitotic index, and presence of residual tumor after initial surgery affect the prognosis and recurrence. ${ }^{11-13}$

The purpose of our study was to evaluate the clinical characteristics, recurrence patterns, surgical management and outcomes, and to identify factors which may affect the survival of early-stage AGCT patients operated at our gynecological oncology department.

\section{MATERIAL AND METHODS}

Our study was retrospectively performed at the Istanbul Kanuni Sultan Suleyman Training and Research Hospital's Gynecological Oncology Department, after obtaining approval from the local ethics committee (KSSTRH, 2018/11/60) with the Declaration of Helsinki.

The hospital database and patient files were thoroughly reviewed. All the patients with earlystage-AGCTs (stage I-II), who were treated between January 1998 and December 2015, were included in our study.

The patients with any other accompanying malignancy and those in the advanced stage (stage III-IV) of AGCT were excluded. Using the hospital database, demographic and clinical characteristics of the patients, including pre-operative CA-125 levels, ultrasound images, surgical techniques, tumor sizes, lymph node involvement, and surgical stage at diagnosis were recorded. Age and tumor size were evaluated for multivariate analysis. Furthermore, recurrence, ACT, and postoperative follow-up outcomes were evaluated. The accuracy of frozen sections (FS) was evaluated in comparison to intraoperatively-performed FS. Patients with incomplete data were excluded from the analysis.

Regarding recurrent cases, parameters such as time to recurrence, additional treatment modalities, and status after recurrence were also recorded. Recurrent and non-recurrent groups were compared based on the prognostic parameters. Operations were classified as fully staged, incompletely staged, or un-staged. The operation was considered fully staged if peritoneal washing and complete pelvic as well as para-aortic lymphadenectomy were performed. If only pelvic lymphadenectomy was performed or an inadequate number of lymph nodes were removed, the patients were considered incompletely staged. If only ovarian cystectomy or oophorectomy and/or hysterectomy were performed, the patients were considered un-staged. Adequate lymph node count for the fully staged procedure was defined as at least 40 lymph nodes ( 25 of pelvic and 15 of para-aortic lymph nodes). ${ }^{14}$ Disease-free survival (DFS) was defined as the time from the date of primary surgery to the detection of recurrence, or the latest observation in patients without recurrence. Overall survival (OS) was defined as the time from the date of primary surgery to death, or the latest observation.

All the statistical analyses were performed using the software Med-Calc (ver. 16.0 for Windows, MedCalc Software, Mariakerke, Belgium). Chisquare test and Student's t-test were used for statistical analysis of unpaired data. Analysis of survival was based on the Kaplan-Meier method, and the results were compared using a log-rank test. Univariate and multivariate Cox regression analyses were used to determine factors affecting survival and were presented as hazard ratios (HR). A $p$-value of $<0.05$ was considered to be statistically significant.

\section{RESULTS}

Forty-one patients with AGCTs were found to meet the study criteria. The clinicopathological characteristics of the patients are presented in Table 1. Median age at diagnosis was 51.4 years. Mean tumor diameter was $81.7 \mathrm{~mm}$. Abdominal or pelvic pain $(61 \%)$ were the most commonly reported symptoms, followed by irregular menstruation (29.3\%). Preoperative endometrial pathology results of 34 patients were available. Among these, eight had endometrial hyperplasia with or without atypia (Table 1).

Surgery was performed as the primary treatment. Detailed surgical and pathological characteristics of the patients are demonstrated in Table 2. Twenty-three cases (56\%) underwent full-staged 


\begin{tabular}{|c|c|}
\hline \multicolumn{2}{|c|}{$\begin{array}{l}\text { TABLE 1: Demographic characteristics of the patients with } \\
\text { adult granulosa cell ovarian tumors. }\end{array}$} \\
\hline & $n=41$ \\
\hline Age (years) & $51.4(28-70)$ \\
\hline Nulliparity (n, \%) & $2(4.9)$ \\
\hline \multicolumn{2}{|l|}{ Ultrasound image } \\
\hline Solid (n, \%) & $33(80.5)$ \\
\hline Cystic (n, \%) & $2(4.9)$ \\
\hline Semisolid (n, \%) & $6(14.6)$ \\
\hline CA125 level (U/mL) & $38.1(1-333)$ \\
\hline Tumor size (mm) & $81.7 \pm 39.2$ \\
\hline \multicolumn{2}{|l|}{ Complaint $(\mathrm{n}, \%)$} \\
\hline Abdominal or pelvic pain & $25(61)$ \\
\hline Abdominal distention & $4(9.7)$ \\
\hline Vaginal bleeding & $12(29.3)$ \\
\hline Bilaterality $(\mathrm{n}, \%)$ & $5(12.2)$ \\
\hline \multicolumn{2}{|l|}{ Preoperative endometrial biopsy $(\mathrm{n}, \%)$} \\
\hline Hyperplasia with or without atypia & $8(19.5)$ \\
\hline No hyperplasia & $26(63.4)$ \\
\hline
\end{tabular}

surgery including total abdominal hysterectomy (TAH), bilateral salphingo-opherectomy (BSO), pelvic and para-aortic lymphadenectomy, while 16 cases (39.1\%) underwent incomplete-staged procedure including $\mathrm{TAH}, \mathrm{BSO}$, and pelvic lymphadenectomy, and the remaining two patients (4.9\%) underwent TAH and BSO procedures only. We observed that the majority of the fully or incompletely staged patients had stage IA disease (26 cases, $63.4 \%$ ), while $17.1 \%$ had stage IC and $14.6 \%$ had stage II disease. FS was performed in only 32 patients and its accuracy was $75 \%$. The median follow-up period was 55.2 months (range 1-168 months). During the follow-up period, three patients (7.3\%) died of the disease. A total of eight patients received ACT after initial surgery (Table 2).
According to the multivariate analyses, FIGO stage $(<\mathrm{IC}$ or $\geq \mathrm{IC})$, age $(\geq 43.5$ or $43.5>)$, and lymphadenectomy in addition to full stage surgery did not influence the DFS or OS (Table 3). In the univariate analyses, age, bilaterality, tumor size, and

\begin{tabular}{|c|c|}
\hline \multicolumn{2}{|c|}{$\begin{array}{l}\text { TABLE 2: Pathologic and surgical characteristics of patients } \\
\text { with adult granulosa cell ovarian tumors. }\end{array}$} \\
\hline \multicolumn{2}{|l|}{ Stage in diagnosis $(n, \%)$} \\
\hline IA & $26(63.4)$ \\
\hline IB & $2(4.9)$ \\
\hline IC & $7(17.1)$ \\
\hline IIA & $0(0.0)$ \\
\hline IIB & $3(7.3)$ \\
\hline IIC & $3(7.3)$ \\
\hline Disease free survival (months) & $53.1(1-168)$ \\
\hline Overall survival (months) & $54.3(1-168)$ \\
\hline Duration of follow-up (months) & $55.2(1-168)$ \\
\hline Recurrence $(n, \%)$ & $4(9.8)$ \\
\hline \multicolumn{2}{|l|}{ Treatment of recurrent tumor } \\
\hline Chemotherapy & $3(7.3)$ \\
\hline Surgery+chemotherapy (sequential) & $1(2.4)$ \\
\hline \multicolumn{2}{|l|}{ Frozen pathology records $(n, \%)$} \\
\hline Correct & $24(75.0)$ \\
\hline Wrong & $8(25.0)$ \\
\hline \multicolumn{2}{|l|}{ Operation type $(n, \%)$} \\
\hline Full staged (tah+bso+pplnd/bso+pplnd) & $23(56.0)$ \\
\hline Incomplete staged (tah+bso+plnd) & $16(39.1)$ \\
\hline Un-staged surgery (tah+bso) & $2(4.9)$ \\
\hline $\operatorname{Died}(n, \%)$ & $3(7.3)$ \\
\hline Adjuvant chemotherapy & $8(19.5)$ \\
\hline Number of removed lymph nodes & $28.8 \pm 18.2(0-75)$ \\
\hline Paraaortic lymphadenectomy $(n, \%)$ & $23(56.0)$ \\
\hline Pelvic lymphadenectomy $(n, \%)$ & $39(95.1)$ \\
\hline Lymph node involvement $(n, \%)$ & $3(7.3)$ \\
\hline
\end{tabular}

tah: total abdominal hysterectomy, bso: bilateral salpingo-oophorectomy, plnd: pelvic lymph node dissection, pplnd: pelvic and paraaortic lymph node dissection.

\begin{tabular}{|c|c|c|c|c|c|c|}
\hline & \multicolumn{3}{|c|}{ Disease-free survival } & \multicolumn{3}{|c|}{ Overall survival } \\
\hline & Hazard ratio & $95 \% \mathrm{Cl}$ & $\mathrm{p}$-value & Hazard ratio & $95 \% \mathrm{Cl}$ & $p$ value \\
\hline Age (<43.5 yr vs. $\geq 43.5$ yr) & 1.0 & $0.4-2.3$ & 0.93 & 1.0 & $0.4-2.3$ & 0.90 \\
\hline Stage $(<\mid C$ vs. $\geq I C)$ & 0.7 & $0.3-1.8$ & 0.51 & 0.7 & $0.3-1.8$ & 0.56 \\
\hline Staging surgery (none/incomplete vs. full) & 1.3 & $0.6-3.1$ & 0.44 & 1.3 & $0.6-3.2$ & 0.43 \\
\hline Lymphadenectomy & 0.5 & $0.1-2.1$ & 0.41 & 0.5 & $0.2-2.1$ & 0.42 \\
\hline
\end{tabular}

Cl: Confidence interval. 
TABLE 4: Results of univariate analysis of preoperative risk factors of patients with lymph node involvement.

\begin{tabular}{|lccc|}
\hline & Hazard ratio & $95 \% \mathrm{Cl}$ & $\mathrm{p}$-value \\
\hline Age $(<43.5 \mathrm{vs.} \geq 43.5)$ & 0.5 & $0.4-068$ & 0.47 \\
Bilaterality & 1.2 & $0.6-2.5$ & 0.58 \\
Tumor size $(\leq 78 \mathrm{~mm}$ vs. $>78 \mathrm{~mm})$ & 1.0 & $0.9-1.1$ & 0.74 \\
Preoperative ultrasound image (solid vs. non-solid) & 0.7 & $0.5-0.9$ & 0.50 \\
\hline
\end{tabular}

Cl: Confidence interval.

\begin{tabular}{|lccc|}
\hline \multicolumn{4}{|c|}{ TABLE 5: Results of multivariate analysis of risk factors of patients with recurrent adult granulosa cell ovarian tumor. } \\
\hline & Hazard ratio & $95 \%$ Cl & p-value \\
Stage $(<\mid C$ vs. $\geq I C)$ & 0.8 & $0.7-1.0$ & 0.68 \\
Staging surgery (none/incomplete vs. full) & 0.7 & $0.6-0.8$ & 0.25 \\
Received adjuvant chemotherapy (stage $\geq I C)$ & 1.1 & $0.9-1.5$ & 0.80 \\
\hline
\end{tabular}

Cl: Confidence interval.

TABLE 6: Clinical outcomes and descriptive data of recurrent ovarian granulosa cell tumors.

\begin{tabular}{|c|c|c|c|c|c|c|c|}
\hline Patient number & Age & $\begin{array}{l}\text { Initial } \\
\text { stage }\end{array}$ & $\begin{array}{l}\text { Primary } \\
\text { treatment }\end{array}$ & $\begin{array}{l}\text { Time to recurrence } \\
\text { (month) }\end{array}$ & Localization & $\begin{array}{l}\text { Recurrence } \\
\text { treatment }\end{array}$ & $\begin{array}{l}\text { Current status } \\
\text { (D or L) }\end{array}$ \\
\hline 1 & 44 & $\mathrm{lb}$ & Incompletely staged & 7 & Liver & CT & L \\
\hline 2 & 38 & \|c & Full staged+CT & 10 & Abdomen nodal and liver & СT & D \\
\hline 3 & 30 & Ic & Full staged+CT & 120 & Abdomen nodal and liver & Surgery + CT & D \\
\hline 4 & 45 & $\| c$ & Full staged $+\mathrm{CT}$ & 3 & Liver & CT & D \\
\hline
\end{tabular}

CT: Adjuvant chemotherapy; L: Alive; D: Dead.

preoperative ultrasound image (solid or not solid) were not observed to influence the involvement of lymph nodes in AGCTs (Table 4).

According to the multivariate analyses, FIGO stage ( $<\mathrm{IC}$ or $\geq \mathrm{IC})$, surgical staging, and CT did not influence the recurrence of AGCTs (Table 5).

The average DFS was 35 months. Three of the four recurrences appeared during the first ten months. Three patients with recurrent disease were treated with chemotherapy and one was treated with chemotherapy after secondary surgery. Three patients were managed by only salvage chemotherapy with paclitaxel and carboplatin. The clinical characteristics of cases with recurrent AGCT are presented in Table 6.

\section{DISCUSSION}

In this study, we evaluated women with early-stage AGCT, who were managed at a tertiary gynecological oncology clinic in Turkey. We observed that parameters such as age, stage, tumor size, and lymphadenectomy were not independent prognostic predictor factors in AGCTs.

AGCTs are uncommon clinical entities, constituting nearly $5 \%$ of all ovarian neoplasia. ${ }^{1,2}$ Ovarian AGCTs may occur at an earlier age and the diagnosis can be made at earlier stages because of the slow proliferation rates of these tumors. They recur late, and the disease prognosis is good. ${ }^{3,4}$ However, because of the slow proliferation rate of these tumors, 
it is difficult to clearly understand the clinical scenario of AGCT, decide on the appropriate treatment, and identify its prognostic factors. The median age for the diagnosis of this tumor is around 50-55 years. ${ }^{5}$ In our study, the median age at diagnosis was 51 years, which was in accordance with that reported in the literature. Although AGCT may be asymptomatic, Sun et al. demonstrated that most patients with AGCTs exhibited symptoms due to the mass-like abdominal distension or symptoms related to the hormone production of these tumors, which were similar to the findings of our study. ${ }^{8}$ In our study, most of the patients (85.4\%) were diagnosed at stage I and the mean tumor diameter at the time of diagnosis was $8.1 \mathrm{~cm}$.

The requirement of complete systematic lymphadenectomy during primary surgery and the prognostic factors for OS and DFS in patients are the most commonly discussed issues about AGCTs. In the previous studies, FIGO stage, tumor diameter, tumor rupture (preoperative or intraoperative), age at diagnosis, mitotic index, surgical method (staged or not), and residual disease after surgery were shown to be the prognostic factors in AGCTs. ${ }^{9} 10,15-18$ In studies with large sample sizes, FIGO stage, tumor size, nuclear atypia, and postoperative residual tumor have been reported to be the major prognostic factors. ${ }^{7,8,19}$ In this study, we evaluated only 41 patients with ovarian AGCTs that were treated in our gynecological oncology department. As a result, FIGO stage $(<\mathrm{IC}$ or $\geq \mathrm{IC})$, age $(\geq 43.5$ or $43.5>)$, lymphadenectomy, and full-staged surgery were not found to be significant prognostic predictors in the multivariate analyses for OS and DFS. Furthermore, we observed that the rate of lymph node involvement in recurrence was $25 \%$ and all the nodal involvements were in the para-aortic area. The involvement of retroperitoneal lymph nodes in recurrence of AGCTs was reported to be $15 \%$ by Abu-Rustum et al., $18.9 \%$ by Sun et al., $25.7 \%$ by Mangili et al., and $50 \%$ by Fotopoulou et al. ${ }^{8,10,20,21}$ In the study by Abu-Rustum et al., $81 \%$ of the patients were not completely staged. The authors suggested full-staged surgery and complete systematic lymphadenectomy, as recurrences appeared to be because of the involvement of microscopic lymph nodes. ${ }^{10}$ In contrast, we observed that full-staged surgery was not a significant prognostic factor for AGCTs. Therefore, in light of our findings, we believe that full surgical staging does not change the prognosis.

Another contentious issue for AGCTs is the use of ACT after surgery. According to the National Comprehensive Cancer Network (NCCN), the treatment recommended after comprehensive staging is the observation or consideration of platinumbased chemotherapy for stage IC, and platinumbased chemotherapy or radiotherapy for the limited disease for stages II-IV, Sun et al. and Homesley et al. demonstrated that ACT was necessary for the prevention of recurrent disease. ${ }^{8,22,23}$ However, AlBadawi et al. showed that ACT had no benefit for advanced stage disease. ${ }^{24}$ Furthermore, Chan et al. reported that the absence of residual disease was an independent predictor of improved survival and ACT did not affect survival. ${ }^{25}$ In our study, surgery after ACT did not influence the rate of survival or the recurrence in comparison to surgery without ACT.

In the present study, two out of 35 stage I patients $(5.7 \%)$ and two out of 6 stage II patients (33.3\%) showed recurrent disease. However, according to the multivariate analysis, the surgical stage was not an independent prognostic factor. Furthermore, we showed that surgical staging and ACT were not independent risk factors for the recurrence of AGCTs. In the literature, the pelvic region has been reported to be the most common site for disease recurrence (16.2-77.4\%), while the liver is shown to be the most common extra-pelvic region for metastasis (6-25\%). ${ }^{8,9,11,16}$ In our study, the liver was found to be the most common site for the first recurrence (100\%). The rate of pelvic metastases was $0 \%$. These results may possibly be due to the more effective measures taken against local recurrence.

Our study has some limitations, primarily because of its retrospective nature. Secondly, we could not investigate the mitotic index level in the possible prognostic factors for AGCT. Nevertheless, this study evaluated AGCT patients in the early stages of the disease and the follow-up periods of the patients were long. 


\section{CONCLUSION}

FIGO stage, age, lymphadenectomy, and full-staged surgery do not influence DFS, OS, or recurrence in early-stage AGCT. Furthermore, age, bilaterality, and preoperative ultrasound image were not independent risk factors for lymph node involvement in AGCTs. Because of the rare occurrence of ovarian AGCTs, more multicenter studies with larger sample sizes are required to determine the possible prognostic factors and strategies for their ideal management.

\section{Source of Finance}

During this study, no financial or spiritual support was received neither from any pharmaceutical company that has a direct connection with the research subject, nor from a company that provides or produces medical instruments and materials which may negatively affect the evaluation process of this study.

\section{Conflict of Interest}

No conflicts of interest between the authors and / or family members of the scientific and medical committee members or members of the potential conflicts of interest, counseling, expertise, working conditions, share holding and similar situations in any firm.

\section{Authorship Contributions}

Idea/Concept: Baki Erdem, Osman Aşıcıŏglu; Design: İlkbal Temel Yüksel, Baki Erdem; Control/Supervision: Özgür Akbayır, Berna Aslan Çetin; Data Collection and/or Processing: Nur Betül Arslan, İpek Yıldız Özaydın; Analysis and/or Interpretation: Berna Aslan Çetin, Osman Aşıcıoğlu; Literature Review: İpek Yıldız Özaydın, Illkbal Temel Yüksel; Writing the Article: Osman Aşıcıoğlu, Baki Erdem; Critical Review: Özgür Akbayır, Suat Can Ulukent; References and Fundings: Suat Can Ulukent, Nur Betül Arslan.
1. Evans AT 3rd, Gaffey TA, Malkasian GD Jr, Annegers JF. Clinicopathologic review of 118 granulosa and 82 theca cell tumors. Obstet Gynecol. 1980;55(2):231-8. [PubMed]

2. Lee YK, Park NH, Kim JW, Song YS, Kang $\mathrm{SB}$, Lee HP. Characteristics of recurrence in adult-type granulosa cell tumor. Int J Gynecol Cancer. 2008;18(4):642-7. [Crossref] [PubMed]

3. Young RH, Dickersin GR, Scully RE. Juvenile granulosa cell tumor of the ovary. A clinicopathological analysis of 125 cases. Am J Surg Pathol. 1984;8(8):575-96.

4. Colombo N, Parma G, Zanagnolo V, Insinga A. Management of ovarian stromal cell tumors. J Clin Oncol. 2007;25(20):2944-51. [Crossref] [PubMed]

5. Schumer ST, Cannistra SA. Granulosa cell tumor of the ovary. J Clin Oncol. 2003;21(6): 1180-9. [Crossref] [PubMed]

6. Kwon SH. A clinicopathologic study of ovarian granulosa cell tumor. J Women's Med. 2010;3(1):12-7. [Crossref]

7. Ohel G, Kaneti H, Schenker JG. Granulosa cell tumors in Israel: a study of 172 cases. Gynecol Oncol. 1983;15(2):278-86. [Crossref]

8. Sun HD, Lin H, Jao MS, Wang KL, Liou WS, Hung YC, et al. A long-term follow-up study of 176 cases with adult-type ovarian granulosa cell tumors. Gynecol Oncol. 2012;124(2):2449. [Crossref] [PubMed]

9. Ayhan A, Tuncer ZS, Tuncer R, Mercan R, Yüce K, Ayhan A. Granulosa cell tumor of the

\section{REFERENCES}

ovary. A clinicopathological evaluation of 60 cases. Eur J Gynaecol Oncol. 1994;15(4):3204. [PubMed]

10. Abu-Rustum NR, Restivo A, Ivy J, Soslow R Sabbatini $\mathrm{P}$, Sonoda $\mathrm{Y}$, et al. Retroperitoneal nodal metastasis in primary and recurrent granulosa cell tumors of the ovary. Gynecol Oncol. 2006;103(1):31-4. [Crossref] [PubMed]

11. Malmström H, Högberg T, Risberg B, Simonsen $\mathrm{E}$. Granulosa cell tumors of the ovary: prognostic factors and outcome. Gynecol Oncol. 1994;52(1):50-5. [Crossref] [PubMed]

12. Schwartz PE, Smith JP. Treatment of ovarian stromal tumors. Am J Obstet Gynecol. 1976;125(3): 402-11. [Crossref]

13. Sehouli J, Drescher FS, Mustea A, Elling D, Friedmann W, Kühn W, et al. Granulosa cell tumor of the ovary: 10 years follow-up data of 65 patients. Anticancer Res. 2004;24(2C): 1223-9. [PubMed]

14. Ayhan A, Salman MC, Velipasaoglu M, Sakinci M, Yuce K. Prognostic factors in adult granulosa cell tumors of the ovary: a retrospective analysis of 80 cases. J Gynecol Oncol. 2009;20(3):158-63. [Crossref] [PubMed] [PMC]

15. Miller BE, Barron BA, Wan JY, Delmore JE, Silva EG, Gershenson DM. Prognostic factors in adult granulosa cell tumor of the ovary. Cancer. 1997:79(10):1951-5. [Crossref]

16. Lauszus FF, Petersen AC, Greisen J, Jakobsen $A$. Granulosa cell tumor of the ovary: a population-based study of 37 women with stage I disease. Gynecol Oncol. 2001;81(3): 456-60. [Crossref] [PubMed]

17. Thrall MM, Paley P, Pizer E, Garcia R, Goff BA. Patterns of spread and recurrence of sex cord-stromal tumors of the ovary. Gynecol Oncol. 2011;122(2):242-5. [Crossref] [PubMed] [PMC]

18. Uygun K, Aydiner A, Saip P, Basaran M, Tas F, Kocak Z, et al. Granulosa cell tumor of the ovary: retrospective analysis of 45 cases. Am J Clin Oncol. 2003;26(5):517-21. [Crossref] [PubMed]

19. Björkholm E, Silfverswärd C. Prognostic factors in granulosa-cell tumors. Gynecol Oncol. 1981;11(3):261-74. [Crossref]

20. Mangili $G$, Sigismondi $C$, Frigerio L, Candiani M, Savarese A, Giorda G, et al. Recurrent granulosa cell tumors (GCTs) of the ovary: a MITO-9 retrospective study. Gynecol Oncol. 2013;130(1):38-42. [Crossref] [PubMed]

21. Fotopoulou C, Savvatis K, Braicu El, Brink Spalink V, Darb-Esfahani S, Lichtenegger W, et al. Adult granulosa cell tumors of the ovary: tumor dissemination pattern at primary and recurrent situation, surgical outcome. Gynecol Oncol. 2010;119(2):285-90. [Crossref] [PubMed]

22. NCCN. Clinical Practice Guidelines in Oncology Ovarian Cancer. Including Fallopian Tube Cancer and Primary Peritoneal Cancer Version $1 ; 2016$ 
23. Homesley HD, Bundy BN, Hurteau JA, Roth LM. Bleomycin, etoposide, and cisplatin combination therapy of ovarian granulosa cell tumors and other stromal malignancies: a Gynecologic Oncology Group study. Gynecol Oncol. 1999;72(2): 131-7. [Crossref] [PubMed]
24. Al-Badawi IA, Brasher PM, Ghatage $P$, Nation JG, Schepansky A, Stuart GC. Postoperative chemotherapy in advanced ovarian granulosa cell tumors. Int J Gynecol Cancer. 2002;12(1):119-23. [Crossref] [PubMed]
25. Chan JK, Zhang M, Kaleb V, Loizzi V, Benjamin J, Vasilev S, et al. Prognostic factors responsible for survival in sex cord stromal tumors of the ovary--a multivariate analysis. Gynecol Oncol. 2005;96(1):204-9. [Crossref] [PubMed] 